\title{
A GENERALISED AMNISTIC MODEL FOR THE DEVELOPMENT OF UNDERWATER TECHNOLOGY
}

Adam Olejnik

Faculty of Mechanical and Electrical Faculty, Polish Naval Academy in Gdynia, Poland

\section{ABSTRACT}

The material proposes a generalised model for the development of underwater technology, understood as a technical means of penetrating and exploring the depths of the oceans. The model was developed on the basis of the previously proposed bifurcation model. The basis and starting point for the development of the model was the analysis of literature. The proposed model indicates that regardless of which technical solution for underwater penetration was developed in the past, it will belong to one of the three defined developmental 'streams' of this technique. Since the proposed model has the characteristic of a flowing stream and is more general than the bifurcation model, its name has been proposed as a generalised amnistic developmental model of the underwater technique.

Keywords: mechanical engineering, marine engineering, underwater works technology.

ARTICLE INFO

PolHypRes 2019 Vol. 68 Issue 3 pp. 59 - 70

ISSN: 1734-7009 elSSN: 2084-0535

DOI: $10.2478 / \mathrm{phr}-2019-0015$

Pages: 12 , figures: 4 , tables: 0

Original article

page www of the periodical: www.phr.net.pl

Submission date: 14.06.2019 r.

Acceptance for print: $18.09 .2019 \mathrm{r}$.

Publisher

Polish Hyperbaric Medicine and Technology Society 


\section{INTRODUCTION}

The underwater world which constitutes the majority of the surrounding planetary reality, which results directly from the hypsographic curve - less than $30 \%$ of the surface of our planet protrudes above the water
(Fig. 1) [1] - has been of interest to the human species for a long time, for hundreds of years, or perhaps since forever. It is therefore not surprising that for centuries people have been trying to build a technique for exploring the underwater part of our world.

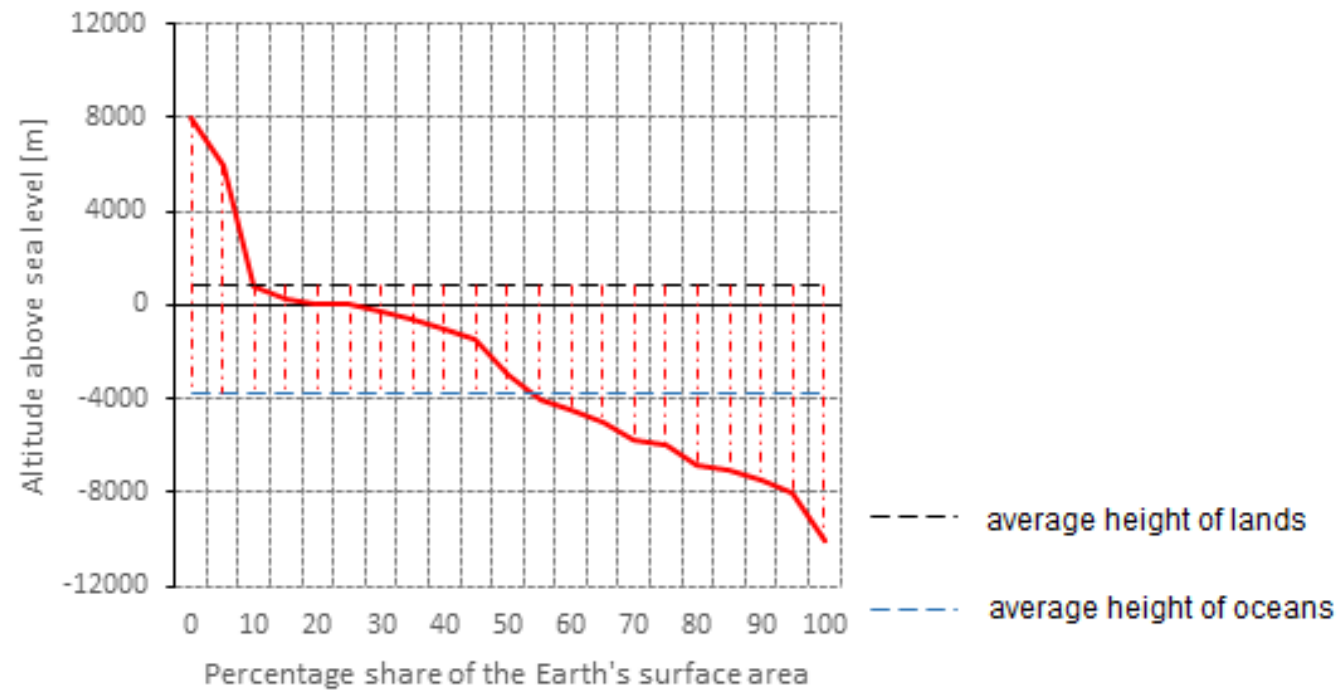

Fig. 1: Hypsographic curve shows the altitudinal and depth structure of the Earth's surface - on the basis of [1].

According to Tadeusz Nowak, science operates with at least 25 different definitions of the term 'technique', where one of the most general defines the term as a means allowing for the use of resources of matter and energy [2]. In this article, the word 'technique' will define the means enabling exploration and exploration of the ocean depths, i.e. underwater technique. Based on the proposed definition of a technique, Nowak points to a number of different and complex determinants of its origin and development. One of the links he analyses is the connection between technological development and scientific progress, where he states that from the time when technology came into contact with science in the 16th century, this connection has been of a feedback nature. However, the issue is more complex, as Nowak writes, and cannot be explained in a simple way. Technological progress is influenced by numerous factors, and scientific development is only one of them, albeit perhaps the most important of them, because usually technical progress is preceded by a scientific breakthrough.

The material concerning the current state of technology of remotely controlled underwater vehicles indicates that their development is directly influenced by market demand, current state of the art and environmental conditions (understood as the pace of economic growth), demand for energy sources and exchange rates [3]. A further factor in the development of technique is the phenomenon which Prof. Orłowski describes as "reverse inventiveness", which has both its bright and negative sides [4]. In the case discussed by Prof. Orłowski, the negative impact is associated with the state's policy on technical development. The example of Prof. Orłowski concerned actions contrary to the mission of an engineer, when in one of the Polish mines a machine was built to enrich the coal output with stones, because state authorities were more interested in the size (tonnage) of the excavated material than in the quality of the coal. However, in underwater technology we can see a positive example of this phenomenon. Each drawing presenting the solution of the diving machine proposed by Klingert presents a diver equipped with an axe [5].

One of the reasons that contributed to Klingert's developing the proposed solution was his willingness to interest landowners in its use, who by decree of the authorities were obliged to remove branches of fallen trees from the riverbed. These two examples clearly show how the current policy of the country where the inventor lives may not have a direct influence on the direction in which the technology will evolve. In the case of underwater technology, a bifurcation model of its development has already been proposed [6]. It is a model closely related to the model of scientific progress and draws heavily from the theory of scientific evolution, indicating the non-linear character of the development of underwater technique. This model can be more generalised as shown below.

\section{DEVELOPMENT OF UNDERWATER TECHNIQUE IN LITERATURE}

On the basis of book publications, it can be concluded that in general the development of underwater technique is presented in a linear and selective way. Practically every publication of a monographic nature and having as their object underwater works technology or medicine, contains at least one chapter on the development of deep-sea technology $[7,8,9,10,11,12,13,14,15]$. Each of the authors points to specific dates and assigns to them the appearance of a new technical solution representing the area of underwater technology that they are discussing. There are also publications of a wider than specialist scope and of a popular scientific nature. These materials also present a linear approach to the development of underwater technology [16,17,18,19,20,21,22]. 
Another type of publication are materials addressed to young people and children, in which the development of the discussed technique is also presented in a linear manner, and sometimes, which is quite understandable, using mnemotechnical methods [23,24]. The last group of publications, which should be mentioned here, are materials devoted directly to the development of underwater technology, among which two types should be distinguished. The first one was connected with an attempt at a comprehensive description of the problem [25,26,27]. The second was connected with the description of a concrete example of a concept and development of a solution [5,28,29,30,31]. In the first case, the authors attempt to chronologically arrange consecutive events related to the development of deep-sea technology, while in the second, they discuss in detail a single case without going beyond its framework.

While analysing the subject matter in the literature it should be stated that several types of publications related to it can be distinguished, which generally represent the same approach to the problem in question. Regardless of the type of publication, we can observe a linear presentation of the problem. The second conclusion that can be drawn after the analysis of the literature is that the knowledge about the development of underwater technology is dispersed and that there are virtually no analyses about the development model of this technique. The authors focus on selecting new solutions, discussing them and putting them in the right place on the time axis.

They do not explore the causes and conditions of the development of the deep-sea technique they describe. All in all, this is a standard approach that does not differ from the accepted methodology. Past phenomena are studied by means of a critical analysis of their remains and sources, and then the established facts are presented chronologically in the form of narrations. In fact, most of these works can hardly be accused of anything, the authors strive to be very reliable in the analysis of artifacts and sources. However, one very serious mistake can be found in the literature, consisting in the widespread quotation of the Treaty of 1534, which was found to have been subject to some manipulation and will be the subject of a separate publication.

There is one item in the abovementioned literature which may be somewhat surprising. It is a book written by Joseph Steward and published in 2011. The publication is based mainly on Internet sources and contains a large number of illustrations, mostly in poor quality, in which short pieces of information are exchanged without any authorial commentaries. For example, the author devoted eight short sentences to the solution proposed by John Lethbridge in 1715. This seems surprising, as Fardell's paper discussing this case in detail has been available since 2010 [25]. And it could be explained interestingly why a wool trader living hundreds of kilometres from the coast became interested in underwater technology.

\section{GENERALISED AMNISTIC MODEL OF DEVELOPMENT OF UNDERWATER TECHNIQUE}

\section{Central point of The MOdel}

The bifurcation model of the development of underwater technique development proposed in the paper
[6] seems to reflect its current progress. A model of this type according to Prof. Michał Heller [32] allows for an easy post factum identification and evaluation of development factors that took place prior to the analysis and research. On the other hand, long-term predictions concerning development trends going far forward will be much less reliable. This model assumes a significant dynamism of the process at the point of bifurcation, the results of which appear to be very unlikely to predict. It is hard not to agree with this position. However, in the development of deep-sea technology we can find one strong and significant moment of bifurcation, which later had a major impact on its entire development. This was the moment when people rejected the Aristotlean dogma of horror vacui and grasped the concept of atmospheric pressure. The first to correctly define the problem and break away from the dogma was Giovania Battista Balliani, who in 1630 stated that 'we live submerged at the bottom of the ocean of elementary air' [33].

This was later demonstrated by Evangelist Torricelli, who, however, as Professor Wróblewski writes, did not perform the experiment for which he is so well known himself. The first person to describe it scientifically was an Italian monk living on Polish soil - Valeriano Magni. Of course, this concerns proof of the existence of a vacuum, since it turns out that in order to understand the concept of atmospheric pressure, people first of all needed to understand the concept of vacuum. It is precisely this moment of bifurcation, which should be emphasised in the scientific progress, that will also be the central point of the generalised model of the development of underwater technique. Everything that follows in the development of this technology will be completely different than before. Pressure is the first enemy of underwater technology. Its presence has an impact on everything, on materials, structures, on the construction of mechanisms and on the technology of their execution. It is pressure which causes that as early as at the depth of ten meters the total force acting on the body of an uncovered human corresponds to the pressure of a medium sized tank, and the deeper it gets, the greater the stress.

\section{THE FIRST BIFURCATION}

Ever since mankind became aware of the concept of pressure in the development of underwater technique, two parallel developmental streams appeared. Looking at the situation post factum, one can assume, without fear of making a mistake of presentism, that these activities were already conscious. Since people were aware of the existence of ominous pressure underwater, representatives of one of the new development branches decided to build a shielding technique to somehow isolate people from the dangerous environment, hence this developmental trend can be called underwater isolationism. The first effectively verified in practice technical solution in this area was proposed by the aforementioned John Lethbridge at the beginning of the 18th century. Progression along these lines of development have helped to produce the one-atmosphere diving suits of today. 


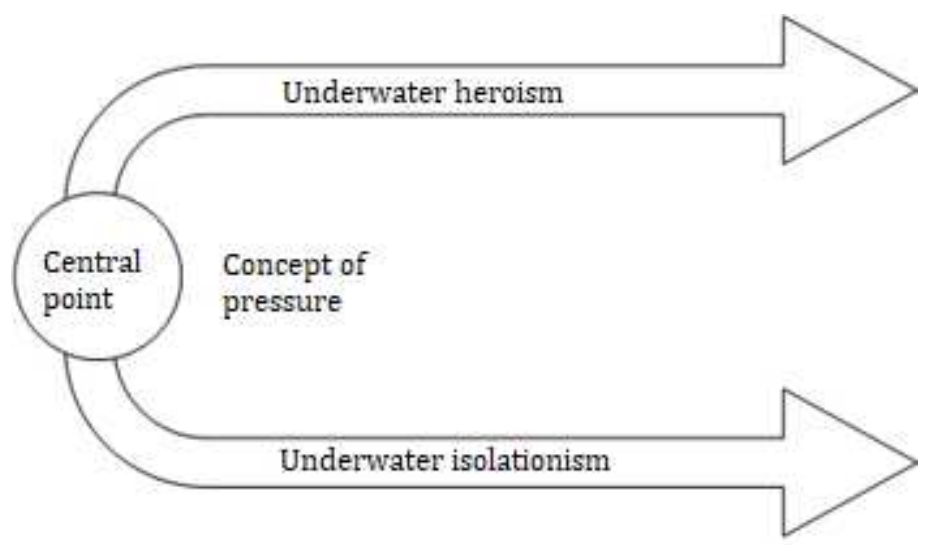

Fig. 2 The first model bifurcation.

In contrast to the representatives of isolationism, the representatives of the second developmental trend emerging from the central point, decided to bravely face the following challenges with the pressure in the depths of the water. What did their courage consist in? They rightly noted that it is problematic to supply a diver with atmospheric air from the surface by means of hoses, which, above all, significantly reduced the operational capabilities and has a major impact on safety. Therefore, they defined the basic function of diving breathing equipment, which is still valid today.

A diver must breathe underwater with air under pressure at a given diving depth. Thus they decided to let the ominous pressure into the diver's body. Taking into account the hitherto prevailing paradigm, it was quite heroic. For these reasons, all of these constructions, whose task was to provide the diver with a breathing mix under the pressure corresponding to the depth the diving was taking place, can be qualified to the developmental stream, which we will call underwater heroism. The author of the first such solution is known from the Gaspard-Gustave Coriolis report from 1839 [34]. He described that in the autumn of 1838 the French Academy of Sciences presented a solution proposed by Manuel Theodor Guillaumet. It was the world's first regulator allowing a diver to breathe compressed air underwater at a pressure similar to that prevailing at the depth of diving. The report stated that the academics considered Guillaumet's idea to be a fortunate and promising one. Today, there is practically no equipment for breathing underwater, regardless of the type of respiratory circuit, which would not work on a similar principle.

It follows from the above that from the central point of the generalised model of underwater technology development two developmental streams emerge: underwater isolationism and underwater heroism, which are concurrent and continue to develop to this day (Fig 2).

\section{THE SECOND BIFURCATION}

However, among the pioneers of underwater technology, more radical inventors appeared. Initially, a technique had to be developed that had nothing to do with deep-sea technology, but over time it became apparent that it could contribute to the emergence of another developmental trend that was more radical than isolationism. It can be assumed that, completely unconsciously, the person responsible for all the confusion was no one else but Nicola Tesla, who in his 1898 patent presented a method for the remote control of ships and vehicles [35]. Then it took less than 60 years and the world saw the first remotely controlled underwater vehicle developed and built by Dimitr Rebikoff [36].

Probably nobody could have anticipated what influence this invention would have on the development of deep-sea technology and that today this would be the most dynamically developing trend of said technology. Since the whole idea of such solutions is based on the principle of an unmanned remotely controlled platform, i.e. there has been a reduction in the human factor from an underwater workplace, this developmental trend can be called underwater reductionism.

This is the second bifurcation in the generalised model of the development of underwater technology, which is separated from the isolationist trend by going further in its concepts, and being more radical than the representatives of this developmental trend. This means that today in the development of deep-sea technology we can observe three main developmental trends which run alongside each other and continuously develop. Two main streams emerge from the central point. The first one is heroism associated with supplying the diver with a breathing mix at the pressure at the diving depth. The second is isolationism associated with the development of equipment separating a human being working underwater from a dangerous environment. And reductionism emerging from isolationism, which is related to the development of devices eliminating the presence of humans at the underwater workstation (Fig. 3).

This approach to the problem explains how underwater technique has been developing from the defined central point to the present day, but it does not explain what preceded bifurcation, i.e. what the beginnings of the underwater technique looked like. 


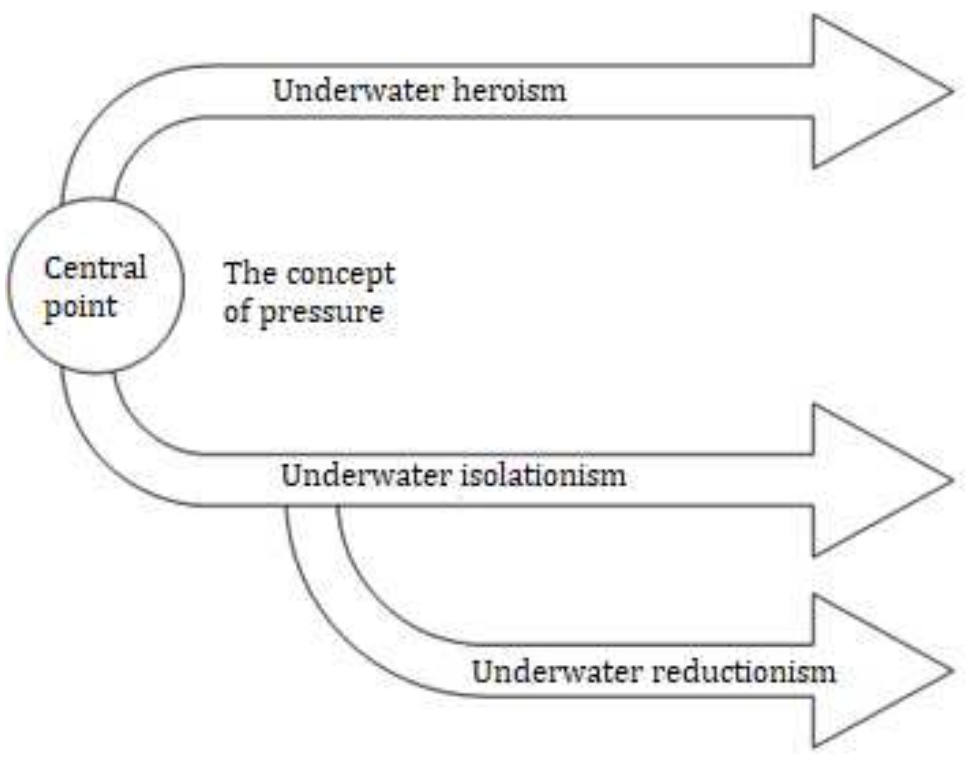

Fig. 3 The second model bifurcation.

\section{THE BEGINNINGS}

We know little about the pioneers of underwater technology. This sentence may come as a bit of a surprise, but it is in fact the case. Information about the origins of the underwater technique is fragmentary, shrouded in a mist of mystery and very often we simply find it in myths and legends. It is also difficult to talk in this case about the use of some sort of technique to conquer the depths, when on the basis of legends and myths we can certainly assume that these were simply breath hold dives. From what has been preserved to this day it is difficult to draw a different conclusion, considering that our source is clay plaques written in a cuneiform.

This is how the myth of Gilgamesh's first dive has been preserved to this day. And interestingly, from this myth we do not learn anything about the manner he performed his feat (in fact, we can only believe it), but we learn why he decided to make the attempt. Next to myths and legends there is indirect evidence, such as furniture inlaid with pearls. After all, divers were needed to create the furniture. This is quite tangible evidence. Moreover, there is information from written sources, such as the code from the island of Rhodes, which defined to what extent a treasure excavated from under water belongs to a diver and made it dependent on the depth from which it was excavated [14].

Literature also provides us with other indirect evidence. Herodotus writes about the divers of a Greek Scylis using hollow reed stems and Tucidydes mentions diving during military operations during the siege of Syracuse [37]. Even Aristotle joins the group of those who carry the message of the pioneers of submarine conquests, describing the deep-sea expedition of Alexander the Great in 320 BC. [27].

Therefore, all knowledge about the beginnings of underwater technology will be based on indirect evidence or presumptions derived from legends and myths. This is not such a comfortable situation as in the case of technical solutions proposed by later inventors, where one can familiarise oneself with a treatise, study or patent issued by them. Considering the available information, a group of pioneers emerges at the beginnings of the underwater technique, albeit using simple technical solutions.

Apart from breathless diving, we have hollow reed stems and an open diving bell. Regardless of the solutions applied by these pioneers, all of them have one thing in common. They were completely unaware of how dangerous a situation they encounter as soon as they put their heads in the water. But despite this ignorance, despite the lack of awareness of physical phenomena and their possible consequences, acting for various reasons, they made attempts which had varying results. It should also be remembered that for a long time their desire to explore and cross the boundaries was often contrary to the prevailing dogmas.

And the position expressed by St. Augustine in the sentence was recommended: "The truth is in what God has revealed, not in what man has blindly guessed." [38]. Thus, the pioneers took the risk not only in contact with the forces of nature. In spite of this, the imperative of the researcher and inventor motivated them to act against this adversity. In a way, they voluntarily subordinated their actions for the cognitive benefit of their entire society or even humanity. Perhaps they did so unwittingly, but from today's point of view, this is how we can look at it. In other words, they had a Promethean approach, and for this reason the whole stream in the development of the underwater technique can be called underwater Prometheanism.

From the above stems, that in the proposed generalised developmental model of the underwater technique, to the left from the central point we firstly see myths and legends, from which, since the time when written sources and artefacts appeared, the trend of Prometheanism emerged (Fig. 4). 


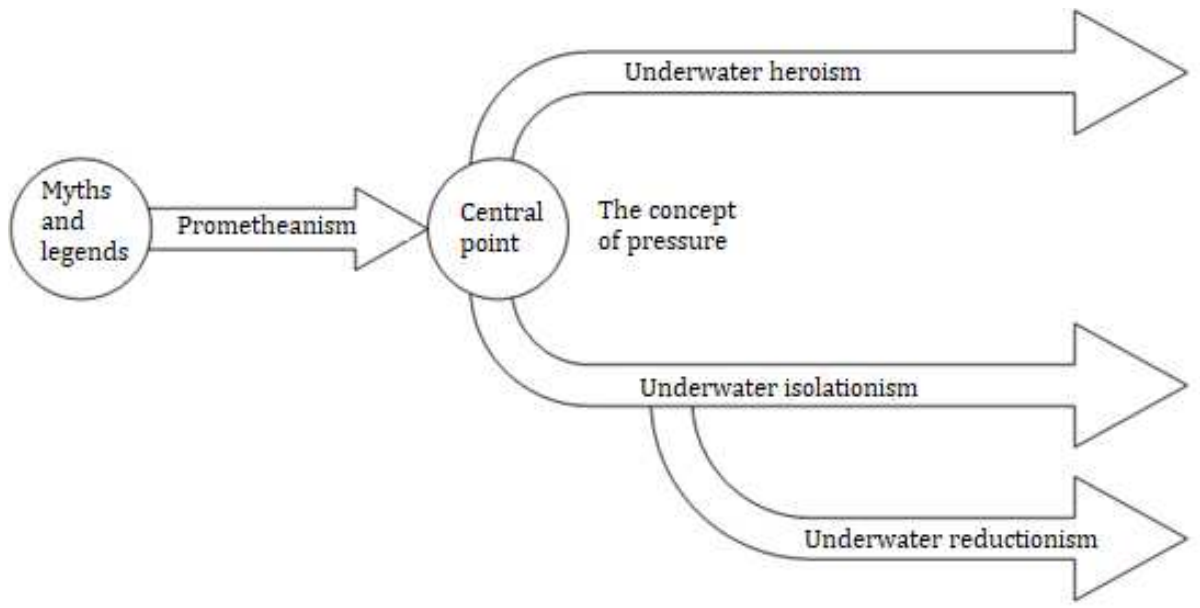

Fig. 4 Generalised model of development of underwater technique.

\section{CONCLUSIONS}

This paper presents a proposal for a generalised model for the development of the underwater technique based on the previously proposed bifurcation model. The basis and starting point for the development of this model were the conclusions from the review of the available literature. First of all, the knowledge on the development of underwater technique is dispersed and fragmentary. Besides, the authors very often note merely the chronology of events, without identifying the causes and conditions for the development of said technique.

Of course, in a written work limited by the confines of an article, not all issues can be addressed, but only indicated. The proposed model indicates that regardless of what kind of technical solution was invented in the past, in consequence of the approach to the solution we will have to refer to one of the three developmental trends of the underwater technique. For instance, regardless of whether it is a diving device with an open or closed circuit of breathing mix, or with concurrent or opposite valves, connected or separated expansion stages - this always will be a device providing the diver with a breathing mix at a pressure corresponding to the diving depth. Thus, they will be constructions belonging to the underwater heroism trend. Even if we let our imagination run free and invent a technique separating the diver from the water with a futuristic force field, which may protect him from the influence of the unfavourable environment, this will be simply an insulation technique inscribed into the trend of underwater isolationism. Whenever we send a remotely controlled or autonomous vehicle to work instead of a human being, the solution will belong to the trend of underwater reductionism.

Everything points to the fact that the development of underwater technology is a strongly meandering stream, which at one time accelerates and at another slows down, or curves heavily to reach a point where it has to recede. Every time it changes course or accelerates, it encounters an unconventional human being or a discovery, innovation or a new scientific theory, which often seems too distant to have an influence on it, and yet it does have quite a significant impact - an example is $\mathrm{N}$. Tesla. And it is not just one stream of progress. It is a river with numerous tributaries and equally numerous outflows, which clearly show that progress in underwater technology has the capacity for branched or bifurcated development. In the multi-threaded technical progress enabling work in the depths and the exploration of their depths, one can at most distinguish central streams at work. This is the proposal the material in this generalised model facilitates. It is a stream, or a current model, and reaching to Latin it can be called an amnistic model (amnis - a current, stream).

The model is more general than the bifurcation model, thus the full name of the proposed model is: a generalised amnistic model for the development of underwater technique. Of course, smaller and local bifurcations will occur in particular branches, but in the development of underwater technology we can presently distinguish three central streams indicated above. The interesting thing about the development of underwater technology is that these streams develop independently and in parallel, coexisting with each other. This means that the predicted imminent departure from diving technologies and their replacement by highly automated technology seems to be premature - at least within certain limits of operational depth. Therefore, the research problems related to the progress of individual developmental trends in underwater technique are equally important and none of them should be depreciated. This implies that a research centre wishing to maintain its leading position in the development of underwater techniques and technologies should conduct multidirectional research whose objectives must not diminish the importance and needs of any of the abovementioned trends.

The author is aware that the approach proposed in the material may seem controversial and for these reasons is open to all voices, which will allow for the clarification of the issues raised. 


\section{REFERENCES}

1. Duxbury A.C.; Duxbury A.B.; Sverdrup K.A.: The Oceans of the World, PWN Warsaw 2002, ISBN 83-01-13780-0, p. 54;

2. Nowak T.M.: On the methodology of scientific work and methodology in the field of history of technology; Kwartalnik Historii Nauki i Techniki ISSN 0023-589X; e-ISSN 2657-4020, Volume 31/3-4 (1986), pp. 815-827;

3. Olejnik A.: The current status of technique of underwater remotely operated vehicles; Polish Hyperbaric Research 3(28)2009 ISSN 1735-7009; e-ISSN 2084-0535; pp. 23-46;

4. Orłowski B.: Historia techniki polskiej; Wyd. Naukowe Instytutu Technologii Eksploatacji Radom 2008 r., ISBN 978-83-7204-704-5;

5. Klingert K.H.: Description of a diving machine; (reprint) The Historical Diving Society London 2002; ISBN 0-9543834-0-0, ed. Jung M., Phillips N., Pettigrew A., Fardell M.;

6. Olejnik A Siermontowski P. Will an underwater robot ever replace the diver? A rather poor progress or a great success?; Polish Hyperbaric Research Vol. 54 Issue 1 2016; ISSN 1735-7009; e-ISSN 2084-0535; p. 7 - 18 DOI: 10.1515/phr-2016-0001;

7. Krzyżak J.: Diving medicine; Ed. KoopGraf Poznań 2006; ISBN 83-909187-5-7;

8. Krzyżak J.: Medicine for divers in a nutshell; Publ. KoopGraf Poznań 2008; ISBN 83-909187-6-5;

9. Kłos R.: Diving with the use of nitrox; Publ. KoopGraf Poznań 1999; ISBN 83-909187-1-4;

10. Kot J., Żabirek T.: Nitrox - a guidebook for divers; Publ. KNOW Gdynia 2006; ISBN 978-83-920563-2-4;

11. Christ R.D., Wernli Sr R.L.: The ROV manual; Elsevier 2014; ISBN 978-0-08-098288-5;

12. Moore St.W., Bohm H., Jensen V.: Underwater robotics; MATE Center 2010; ISBN 978-0-9841737-0-9;

13. Ruppe C.V., Barstad J.: Underwater archeology; Kluwer Academic/Plenum Publishers 2002; ISBN 0-306-46345-8

14. Beebe W.: 923 metres into the ocean; Publ. Trzaska Evert i Michalski 1935;

15. Przylipiak M., Witkowski M.: Diving in self-contained air apparatuses and rescuing the drowning, Ed. MON 1977;

16. High B.: Beneath the sea; Best Publishing Company 1998, ISBN 0-941332-67-5;

17. Guillerme D. J., Rivoire J.: Traite de plongee; Dunod 1955;

18. Vaissiere R.: I'Homme et le monde sous-marine; Liberaire Larousse 1969;

19. Marx R.F.: Deep deeper deepest; Best Publishing Company 1998, ISBN 0-94-1332-66-7;

20. Grouef St.: L'Homme et La mer; Larousse 1973'

21. Jackson R.M.: Essentials of underwater photography; Best Publishing Company 2000, ISBN 0-941332-77-2;

22. Stewart J.: Exploring the history of hyperbaric chambers, atmospheric diving suits and manned submersibles; Xlibris Corporation 2011, ISBN 9781-4568-5722-6

23. Foust D.R.: Underwater robots; PowerKids Press 2017, ISBN 978-1-4994-2186-6;

24. Mountain A.: Diving - A Guidebook; Publ. Galaktyka 1997, ISBN 83-86447-91-5

25. Collective work: History of diving, Publ. Almapress 2002, ISBN 83-7020-312-4;

26. Hussain F.: Living underwater; Praeger 1970;

27. Gussman J.: Man's conquest of the depths; Publ. Morskie 1984, ISBN 83-215-4047-3;

28. Fardell M.: John Lethbridge; The Historical Diving Society 2010, ISBN 978-0-9543834-4-2;

29. Fardell M., Phillips N.: Jacob Row - A demonstration of the diving engine; The Historical Diving Society 2000, ISBN 0-948065-39-7;

30. Harris G.L.: Ironsuit, the history of the atmospheric diving suit; Best Publishing Company 1994 r., ISBN 0-941332-25-X;

31. Kowalska K., Wasiak J.: Karl Heinrich Klingert - the Wrocław citizen, Publ. Muzeum Nurkowania 2016, ISBN 978-83-942616-0-3;

32. Heller M.: Philosophy of science; Publ. Petrus 2009, ISBN 978-83-927267-7-7;

33. Wróblewski A.K.: History of physics, PWN 2007, ISBN 978-83-01-14635-1;

34. Coriolis G.G.: Rapport sur une cloche a plongeur inventee par M. Guillaumet, Comptes Rendus Hebdomadaire des Seances de L'Academie des Sciences, Vol. 9, July - December Paris 1839, pp. 363 - 366;

35. Tesla N.: "Method of and apparatus for controlling mechanism of moving vessels or vehicles" USA Patent Office 1898, Patent No 613 809;

36. Olejnik A.: he development of the technique of underwater remotely operated vehicles; Polish Hyperbaric Research 3(28)2009 ISSN 1735-7009; e-ISSN 2084-0535; pp. 7 - 22;

37. Miller J.W., Koblick I.G.: living and working in teh sea; Five Corner Publications Ltd. 1995, ISBN 1-886699-01-1;

38. Bynum W.: A short history of science; Publ. RM Warsaw 2016, ISBN 978-83-7773-556-5; p. 51.

dr hab. inż. Adam Olejnik, prof. AMW

Akademia Marynarki Wojennej

Zakład Technologii Prac Podwodnych

81-127 Gdynia

ul. Śmidowicza 69

e-mail: a.olejnik@amw.gdynia.pl 